\title{
A RESISTÊNCIA DO PASSADO: CONTORNOS DO GÓTICO EM "THE FLUTED GIRL"
}

André Cabral de Almeida Cardoso (UFF)

Bárbara Bravo Pires Ferreira (UFF)

Recebidoem 09jan 2020. André Cabral de Almeida Cardoso é Doutor em Aprovado em 11 mai 2020.

Literatura Comparada pela New York University, e é professor associado de Literaturas de Língua Inglesa na UFF, atuando tanto na graduação quanto na pósgraduação (Mestrado e Doutorado). Suas publicações mais recentes incluem os artigos "A Flame Deluge, a Waterless Flood: Two Dystopian Narratives on the End of Days" (Revista Brasileira de Literatura Comparada, v. 20, n. 33, p. 16-41, 2018), "Caught In Between: The Conflicted City in DMZ" (de genere, n. 4, p. 43-62, 2018) e "Precarious Humanity: The Double in Dystopian Science Fiction" (Gragoatá, v. 23, n. 47, p. 888-909, 2018). Coordena o grupo de pesquisa Interferências: Literatura e Ciência, além de ser membro do grupo de pesquisa Estudos do Gótico e do grupo de trabalho Vertentes do Insólito Ficcional (ANPOLL). Áreas de interesse: narrativas distópicas e de ficção científica, o gótico, histórias em quadrinhos. Lattes: http://lattes. cnpq.br/5519234534029741

Bárbara Bravo Pires Ferreira é Mestranda em Estudos de Literatura na subárea de Literaturas de Língua Inglesa na UFF, desde 2019, com bolsa fomentada pela CAPES. Áreas de interesse: Literatura distópica, literaturas de língua inglesa. Lattes: http://lattes.cnpq. br/3625074648619034. 
Resumo: O presente artigo propõe uma leitura do conto distópico "The Fluted Girl" (2003), de Paolo Bacigalupi, centrada nos possíveis desdobramentos do gótico presentes no texto. Partimos da compreensão do conto como uma narrativa que tenta representar os mecanismos de consumo e poder através de uma visão negativa do mundo, que o aproxima das noções de gótico tal como apresentadas por Botting (1999) e França (2017), associando-as com os impactos dos avanços tecnológicos sobre a sociedade. Além disso, analisamos as configurações corporais das personagens, sejam elas humanas ou não, como evidência dessas influências do gótico sobre a distopia. Palavras-chave: Gótico; Distopia; Monstruosidade.

Abstract: The article offers an interpretation of Paolo Bacigalupi's distopian short-story "The Fluted Girl" (2003), focusing on the possible unfolding of the gothic presented in the text. It works with the assumption that this short-story tries to represent consumer mechanisms and power through a negative view of the world, which approximates it to the notions of the gothic presented by Botting (1999) and França (2017), combining it with the impacts of technological advances over society. Moreover, we analyze the characters' bodily compositions, whether they are human or not, as evidence of those influences of the gothic over dystopia.

Keywords: Gothic; Distopia; Monstruosity.

No último capítulo de Liquid Times, Zigmunt Bauman, não sem uma certa dose de ironia, traça os contornos de uma utopia contemporânea, que, ao contrário das utopias clássicas surgidas a partir do Renascimento, não seria mais uma projeção de uma sociedade ideal para um local distante ou para o futuro, mas uma utopia vivida no presente e sem um fim previsível. Bauman 
se vale das imagens dos jardineiros e dos caçadores para estabelecer um contraste entre o desejo de um planejamento racional rumo a uma sociedade aperfeiçoada - o sonho dos jardineiros, os utopistas tradicionais - e a busca pelo sucesso ou pela simples sobrevivência por parte dos caçadores, membros de uma utopia pós-moderna caracterizada pelo imediatismo, pelo esforço contínuo da competição e pelo individualismo exacerbado. Nessa caçada evocada por Bauman, o triunfo e o fracasso são vistos como dependendo única e exclusivamente do indivíduo - daí a necessidade de um constante aperfeiçoamento individual ou, de forma mais radical, da criação de um novo "eu", mais desejável e eficiente, a fim de permanecer na corrida e não ser relegado à marginalidade, mas nunca estático e acabado, de modo a permanecer sempre adaptável a circunstâncias em constante alteração. Assim, a possibilidade de se tornar outra pessoa substituiria a ideia de salvação ou redenção, e envolveria a transformação das nossas personalidades, dos nossos hábitos, das nossas maneiras de nos vestirmos e do nosso próprio corpo (BAUMAN, 2008, p.105-106).

Para Paula Sibilia, essa busca permanente do aperfeiçoamento do indivíduo está relacionada a um ideal de perfectibilidade do ser humano que remonta ao Renascimento, a mesma época em que surgiram as primeiras utopias. No entanto, seriam as sociedades baseadas na economia capitalista que teriam inventado "o leque mais abundante de tecnologias para a moldagem de corpos e de subjetividades" (2015, p.13-14). Se, por um lado, esse trabalho de transformação do humano abriria novas possibilidades, o que leva Sibilia a apontar para o surgimento de uma evolução artificial, 
ele também traria enormes riscos, uma vez que é profundamente influenciado pelas necessidades do mercado. Assim, corpos e identidades se tornam passíveis de controle e manipulação rumo a uma maior eficiência, a um aumento de produtividade e a um maior poder de consumo. Tornando-se "mais permeável, projetável, reprogramável" com o predomínio crescente da "tecnociência, da mídia e do mercado", o corpo humano perde sua solidez e sua definição clássica, convertendo-se num ponto de crise do próprio projeto humanista, uma vez que a própria noção de ser humano em que este se apoiava está sob questão (SIBILIA, 2015, p.16-18).

Não é à toa, portanto, que Eduardo Marks de Marques argumenta que, enquanto a literatura utópica clássica é um produto do Renascimento, sua manifestação contemporânea tem sua origem no lluminismo, com sua inclinação para o cientificismo (2013, p.30). Segundo Marques, a crescente influência da tecnologia na vida cotidiana, aliada a uma lógica de mercado que depende da constante renovação do desejo do indivíduo por bens de consumo, faz com que as distopias produzidas na virada do século $X X$ para o $X X I$ se centrem na questão do corpo, alvo não só do aperfeiçoamento via tecnologia, mas também foco da manipulação e manutenção do desejo (2014, p.17-19). Esse foco no corpo - ligado, como vimos acima, à própria desestabilização do conceito do humano - seria, para Marques, o resultado final da democracia liberal e da ação do capitalismo (2013, p.38). Se, portanto, as distopias contemporâneas deixam de privilegiar a representação de Estados totalitários e das estruturas políticas que tornam possíveis esses Estados, é porque devem dar conta não só da apropriação do sonho utópico da perfectibilidade 
humana pela lógica do mercado, mas também da radicalização do processo de individualização a que Bauman se refere e que implica uma reconfiguração do poder.

Trata-se de uma exacerbação do controle metódico e detalhado sobre o corpo a que Foucault se refere em Vigiar $e$ punir (2006, p.161-162), da tentativa de moldar o funcionamento e organização do corpo em todas as suas atividades, numa ação coercitiva constante que busca justamente aumentar sua eficiência. Mas trata-se, também, de uma ação descentralizada, que age cotidianamente não só sobre todas as atividades humanas, mas também sobre o próprio desejo individual, constantemente cooptado, transformado e redirecionado. Para além das tecnologias que efetivamente agem sobre o corpo, o que confronta as distopias contemporâneas é uma questão de representação, o problema de como dar visibilidade a mecanismos de poder que não partem mais de um centro identificável, mas se imiscuem, muitas vezes de forma quase imperceptível, em todas as ações do dia a dia. O corpo surge como uma forma de dar uma representação concreta e dramática a essas instâncias de poder, a que ele empresta sua própria visibilidade.

Tentativas nesse sentido já se fazem sentir antes da virada distópica para o corpo, e fora da literatura distópica propriamente dita. De acordo com Fred Botting, as teorias científicas e a inovação tecnológica muitas vezes são usadas como imagens para a alienação humana nas narrativas góticas desde o século XIX (1999, p.8), David Punter e Glennys Byron relacionam o surgimento do gótico na literatura às transformações socioculturais trazidas pelo início da Revolução Industrial, que 
eles também associam ao isolamento e à alienação do indivíduo, e também ao questionamento da própria natureza do humano, ameaçada por uma crescente mecanização (2004, p.20). Para Júlio França, a literatura gótica codificou "um modo de figurar os medos e de expressar os interditos de diversos grupos sociais", e expressaria os "medos e ansiedades da experiência moderna" (2017, p.2492-2493). É fácil perceber, portanto, a profunda afinidade entre o gótico e a distopia, que compartilhariam uma visão negativa do mundo e das estruturas sociais, além de uma profunda desconfiança em relação à influência cada vez mais forte da tecnociência, constituindo-se ambos como um meio de interpelar a modernidade.

É possível, então, que essa interseção entre a distopia e o gótico se torne ainda mais clara no caso dessas narrativas apontadas por Marques em que o corpo tenha um papel tão central - o corpo como objeto de manipulação e intervenção de um poder que se impõe, ou como sofredor de medo ou dor. Nosso objetivo neste artigo é discutir um conto distópico com fortes elementos de ficção científica em que o corpo se apresenta literalmente como o campo de embate de forças sociais, culturais e tecnocientíficas.

Botting fala de uma dispersão do gótico a partir do século $X X$, do aparecimento de seus traços numa diversidade de meios e gêneros diferentes (1999, p.9), o que aponta para uma visão, comum na crítica mais recente, do gótico como um modo de expressão, e não como um gênero claramente definido. No entanto, o que chama a atenção em "The Fluted Girl", conto de Paolo Bacigalupi publicado originalmente em 2003 que será o objeto de nossa análise, é que a narrativa retoma muitos dos 
elementos que caracterizaram a literatura gótica durante a sua formação no final do século XVIII, não de forma dispersa, mas como elementos centrais da narrativa, numa espécie de retomada paródica do gótico original como elemento de significação.

A premissa central do conto, que serve de base para o desenvolvimento de todo o enredo, já faz uma referência direta às obras de Ann Radcliffe, que tanto contribuíram para a consolidação do gótico no final do século XVIII. Lidia, a "menina flautada" do título, se encontra aprisionada no castelo de Belari, senhora de um feudo sobre o qual exerce um poder absoluto e que é apresentada de forma quase caricatural como uma nova versão do vilão gótico. A inversão de gênero do vilão, agora transformado numa mulher, parece desestabilizar a função ideológica do enredo radcliffeano, que teria o propósito, como afirma Markman Ellis (2003, p.52), de denunciar os excessos do patriarcalismo, no qual a figura do pai era imaginada como um reflexo do poder absoluto do rei, num jogo de espelhamento em que as duas instâncias de autoridade - a do pai e a do rei - se reforçavam mutuamente. No entanto, o caráter absoluto desse poder se mantém, ainda que deslocado da configuração de gênero mais típica do patriarcalismo (o que abre a possibilidade de a vilã ser também uma vítima, como veremos mais adiante). Esse deslocamento é reforçado por um outro, de ordem cronológica, pois não só o conto foi publicado nos primeiros anos do século $\mathrm{XXI}$, quando o poder absoluto do rei já não é mais um problema das sociedades ocidentais, mas também - e isso é o mais importante - sua trama se passa não num distante passado feudal, mas num futuro caracterizado por uma tecnologia extremamente avançada. A primeira função dessa retomada da 
situação central do enredo radcliffeano, o aprisionamento da mocinha num castelo labiríntico escancaradamente anacrônico, é, portanto, evocar a própria tradição do gótico em sua manifestação mais reconhecível (mais caricatural, seria possível dizer) e misturála à ficção científica. Ao mesmo tempo, ao desancorar a questão do poder absoluto de seu contexto histórico e literário original, "The Fluted Girl" tematiza a própria natureza do poder. Se os excessos do poder são uma preocupação central do gótico e se, como Punter e Byron argumentam (2004, p.273), este consegue se adaptar com grande sucesso às diferentes representações do poder ao longo do tempo, cabe nos perguntarmos o que esse retorno a uma imagem do poder ligada às primeiras manifestações do gótico pode significar nesse conto.

Nesse sentido, é interessante que Lidia nos seja apresentada pela primeira vez quando está escondida na despensa do castelo, em meio a jarros de conserva e mantimentos. É como se, metonimicamente, Lidia fosse apenas mais uma das mercadorias produzidas pelo feudo ou consumidas por ele - o que de fato ela é, já que seu corpo é fruto de uma intensa manipulação tecnológica de Belari, que pretende transformar a moça numa estrela midiática que irá lhe trazer enormes lucros. No entanto, o esconderijo de Lidia é um espaço que ela consegue criar para si mesma a fim de escapar, ainda que temporariamente, do controle de Belari. É, portanto, um espaço de frágil autonomia, bastante reduzido, que lembra o quarto de Emily St. Aubert no castelo de Udolfo, ou o pequeno aposento em que Ellena, outra protagonista de Radcliffe, se refugia durante seu aprisionamento em um convento em $O$ italiano. Tratase de espaços que fornecem uma proteção precária, um momento 
passageiro de expansão do indivíduo, ainda que rigorosamente circunscrito e sempre passível de invasão. Eles não oferecem uma fuga efetiva, já que fazem parte da prisão em que essas heroínas acossadas se encontram, mas permitem a liberdade através do recolhimento em si mesma e do alheamento provisório em relação à estrutura opressiva que envolve essas personagens. Nos romances de Radcliffe, assim como no conto de Bacigalupi, apontase para uma noção de subjetividade moderna, que a tradição gótica ajuda a criar, associada à privacidade e à introspecção, mas sempre ameaçada pela pressão invasiva da sociedade, que lhe é externa, mas da qual, paradoxalmente, não deixa de fazer parte.

Essa fragilidade da identidade de Lidia é marcada de forma concreta pela fragilidade de seu próprio corpo. Ao mesmo tempo, a maneira como esse corpo nos é apresentado no conto reforça a conexão entre uma subjetividade privada e o segredo ou o mistério. De início, há apenas indicações da anormalidade desse corpo através de menções esparsas a algumas de suas características. Sabemos, por exemplo, que seu esqueleto é frágil, podendo se quebrar ao menor impacto ou pressão, que Lidia é pequena demais, que é extremamente pálida, que enquanto uma colega de infância cresceu e se tornou uma mulher adulta, ela permaneceu como uma menina à beira da adolescência. Além disso, nos primeiros parágrafos do conto, ela é mencionada pelo narrador apenas como "a menina flautada". Desse modo, Lidia é definida apenas a partir da sua função, que, no entanto, permanece misteriosa. Só perto do final do conto é que vamos compreender que Lidia é de fato uma flauta viva: seus ossos são ocos, com orifícios ligados a chaves de metal, como um instrumento de sopro. Lidia se mostra 
desde o início como a encarnação de pelo menos dois modelos da heroína gótica: a moça inocente e perseguida, à la Ann Radcliffe, escondida num pequeno espaço de frágil segurança e privacidade no meio do castelo medieval em que está presa; e a jovem pálida, frágil e associada à morte, lembrando tantas figuras de Poe, e cuja aparência artificial - pois todo o seu corpo é cuidadosamente manipulado ou mesmo fabricado - lembra também o fascínio do gótico com a ilusão, com a criação de efeitos calculados.

Assim, o momento em que o corpo de Lidia adquire uma certa coerência ao ter sua função esclarecida é também aquele em que ele se revela monstruoso, e sua coerência se vê ameaçada em outro plano. Uma mistura do infantil com o adulto, do natural com o sintético, do ser humano com o instrumento, ele promove a mistura de categorias que Noël Carroll (2004, p.31-33) identifica com o monstro. É também um corpo monstruoso porque se duplica: Lidia tem uma irmã gêmea que sofreu as mesmas alterações e com a qual realiza um dueto musical em que uma sopra no corpo da outra. Relativiza-se, assim, a distinção entre o indivíduo e o outro, ao mesmo tempo em que a performance das gêmeas, descrita em tons abertamente eróticos, embaralha arte e pornografia.

A partir das construções desses corpos, é interessante observar que a amostra mais aparente de monstruosidade no conto ironicamente recai em Lidia, a heroína da narrativa. É um fator que subverte a expectativa de que a monstruosidade estaria atribuída somente aos antagonistas. Mesmo que as ações causadas pelos vilões do conto, como Belari e Vernon, em conjunto com o aspecto animalizado de Burson, o principal capanga de Belari, os aproximem das noções de monstruosidade, é na ideia de uma menina flautada, 
que se apresenta como aberração de estimação de Belari, que a monstruosidade afirma-se enquanto forma de demonstrar o poder.

Se o monstro patrulha as margens da cultura e do humano, como Punter e Byron (2004, p.263) argumentam, indicando os limites que não devem ser ultrapassados, neste caso essas fronteiras se mostram porosas. Para Punter e Byron (2004, p.264), a literatura gótica chama atenção para os processos de criação do monstro, para seu caráter de construção, o que por sua vez desnaturaliza o humano ao mostrar que este também é um produto de uma luta constante na construção e reconstrução discursiva do poder. O corpo de Lidia, sendo fruto da ação direta de Belari e ameaçando a imagem que a menina tem de si mesma, se encontra no centro de uma disputa desse tipo, que sua condição de construto busca explicitar. Desse modo, ele cumpre outra função que Jeffrey Cohen (1996, p.6) associa ao monstro, a de introduzir ou manifestar uma crise.

A crise em questão diz respeito à própria noção moderna de identidade. Em sua monstruosidade, o corpo de Lidia é a marca de sua individualidade, daquilo que a distingue dos demais, uma aberração das normas que o leitor pode identificar com a normalidade. Por outro lado, aquilo que o torna único pode ser duplicado em sua irmã. Ao mesmo tempo em que ameaça distinções e, portanto, se mostra subversivo, ele assume essa condição através da ação explícita de um poder que lhe é alheio e de acordo com a lógica de consumo que rege a sociedade delineada em "The Fluted Girl". É fonte de estranhamento, mas parece estranho à própria Lidia, que não o reconhece como seu corpo original, o corpo de sua infância, anterior à interferência 
de Belari. Parece o fruto mais acabado do sonho humanista do aperfeiçoamento do ser humano que discutimos acima, já que é construído através de um processo planejado, mas trata-se de um processo que foge ao controle do próprio sujeito, ao qual não traz nenhum benefício.

O que "The Fluted Girl" parece querer demonstrar é que, na contemporaneidade, a construção da identidade se dá necessariamente numa crise e que ela é, em grande parte, monstruosa. O corpo se torna o campo de embate entre a instrumentalização do sujeito e sua libertação via indeterminação e estranhamento. A retomada insistente de elementos góticos para representar esse processo é uma indicação de que essa crise já se preparava no momento de consolidação do gótico no final do século XVIII, período em que se consolidava também a noção moderna de identidade. A imagem gótica de um "eu" acossado e marginalizado, que busca um espaço de privacidade e recolhimento em meio à estrutura de poder em que está forçosamente inserido, aponta para uma identidade que se forma em tensão com as pressões sociais às quais se vê forçado a se integrar, ao mesmo tempo em que sua autonomia depende de um certo alheamento e distanciamento. Os clichês da narrativa gótica incorporados pelo conto de Bacigalupi a antagonista que parece uma feiticeira capaz de qualquer proeza através da tecnologia, o castelo labiríntico em que a protagonista pode a qualquer momento cair nas garras de guardas animalizados através da engenharia genética, os atos de crueldade exagerada dos vilões - se tornam elementos excessivos que apontam não só para uma apropriação brincalhona da tradição gótica, mas também para uma leitura alegórica dessa tradição. 
Levando-se em conta essa apropriação em tom de exagero de elementos do gótico, assim como a importância desses elementos na construção de sentidos do conto, entende-se que existe uma tendência paródica no texto, visto que: "ao contrário da sátira, a paródia torna 'a vítima' ou seu objeto de ataque, parte de sua própria estrutura, e assim sua recepção é - até certo ponto -, influenciada pela recepção do seu objeto de crítica, o qual faz parte do texto do parodista" (ROSE, 1993, p.79, tradução nossa) ${ }^{1}$. Desse modo, compreendemos a noção de paródia no conto "The Fluted Girl" através do uso de elementos góticos em sua narrativa como objeto de ataque, que ao mesmo tempo se torna parte da estrutura distópica apresentada. Há, por um lado, uma distopia que se apresenta com certos elementos futurísticos e inovadores, pelas noções de desenvolvimento científico e de imortalidade através do uso da droga Revitia, e que faz uma crítica ao culto de personalidades e à cultura midiática contemporânea, enquanto que, por outro lado, existe uma forte representação de elementos góticos que parecem ter a função de construir uma ponte entre passado e presente na narrativa.

Desse modo, o retorno fantasmagórico do passado que, como indica Júlio França (2016, p.2492), seria um dos elementos recorrentes da narrativa gótica, se traduz aqui no retorno fantasmagórico do próprio gótico como gênero, e também no retorno de um passado medieval, aparentemente incompatível com os avanços tecnológicos que desempenham um papel central na narrativa. Produz-se, então, um entrecruzamento temporal que é

1 "Unlike satire, the parody makes 'the victim', or object, of its attack a part of its own structure, and its reception is thus to some extent influenced by the reception of the object of its criticism, the text which is made a part of the parodist's text" 
essencial para a consolidação da crítica distópica realizada no texto. O passado feudal surge como depositário de um poder absoluto o poder do senhor sobre seus servos - que se imiscui em relações sociais e econômicas típicas do presente, mas levadas ao exagero através de sua extrapolação para o futuro. Desse modo, o caráter arbitrário dessas relações, a carga de exploração que elas envolvem, se explicita; o fato de que essas são relações de poder marcadas pela desigualdade se torna ainda mais visível pela forma quase caricatural como os elementos góticos são articulados, reforçando a crueldade e a vilania dos personagens negativos, que se inserem numa cadeia de dominação: Lidia e sua irmã são exploradas por Belari, uma atriz de sucesso, que por sua vez é explorada por seu empresário. As relações econômicas e profissionais que regem a indústria do entretenimento se convertem em relações cruas de despotismo em que os indivíduos são despidos de sua autonomia e se encontram em constante ameaça, ao mesmo tempo em que a violência do poder se manifesta em castigos físicos ou abusos sexuais. Como se pode ver no caso de Belari, o prestígio gerado pela fama se converte em dinheiro, que por sua vez se converte em poder tirânico, prontamente ancorado na representação física do castelo e do domínio sobre um território.

Essa superposição de diferentes temporalidades intensifica o mecanismo do estranhamento que M. Keith Booker (1994, p.19) e Maria Varsam (2003, p.206) indicam como a principal estratégia formal das narrativas distópicas. As distopias se apoiam justamente no contraponto entre o presente do leitor ou do autor e um futuro em que traços desse presente surgem distorcidos através do exagero. Dessa forma, o mundo 
representado na narrativa distópica é reconhecível para o leitor, ao mesmo tempo em que se mostra pouco familiar, o que por sua vez leva o leitor a desnaturalizar a realidade em que vive, vendo-a com um olhar mais crítico. "The Fluted Girl" acrescenta um terceiro elemento a esse jogo de estranhamento ao introduzir na narrativa o passado feudal, que assombra o presente e o futuro com a possibilidade de sua repetição. Se, por um lado, essa intrusão do passado promove um maior senso de historicidade ao mostrar que o presente faz parte de uma cadeia histórica, o conto desconstrói a noção de um progresso linear ao apontar que o futuro pode ser na verdade um recuo a estruturas políticas e sociais que se julgavam ultrapassadas. Além disso, a narrativa dá a entender que o poder despótico em sua modalidade mais crua é sempre uma presença potencial, independentemente do contexto social em que se manifesta, um resquício animalizado da natureza humana que pode explodir a qualquer momento. Esse traço é marcado, mais uma vez, por Burson, o guarda-costas de Belari, que, apesar de ser um produto da engenharia genética mais avançada, apresenta fortes traços de agressividade animal, ou pelos atos da própria Belari, que incluem a tortura física a que submete Lidia e sua irmã em seu processo de transformação e o assassinato com forma de punição pela revolta. Trata-se de eclosões de um passado primitivo e bárbaro frequentemente associado à ficção gótica (PUNTER, 2013, p.4) e sempre apresentadas sob o viés do excesso. Assim, numa narrativa que aborda a dinâmica da indústria do entretenimento, o gótico, retomado numa chave paródica, surge em seus aspectos mais melodramáticos, bastante 
explorados pela cultura de massas, reforçando um dos temas do conto em sua própria forma e fechando todo o universo ficcional na mesma lógica de consumo cultural.

Todo esse jogo também faz parte da construção de uma atmosfera gótica pelos detalhes na espacialidade que também fazem parte da imagem distópica da sociedade representada no conto. Há um contraste definido pelo narrador entre Lidia, a personagem principal, e o castelo, desde a primeira linha do conto, marcado pelo uso de adjetivos para estabelecer com intensidade a oposição entre o ambiente e o corpo dela - como as mãos pequenas e pálidas contra a escuridão do castelo. E é nesse reforço de contrastes que encontramos novamente reflexos de narrativas góticas como as de Anne Radcliffe. Neste caso, Lidia é a representação de uma mocinha que, mesmo presa em um castelo, parece subverter sua posição com sua revolta final contra Belari e, por fim, pode ser considerada mártir ou heroína da história.

Além disso, a escolha do castelo, com sua grandiosidade labiríntica, combinada com a noção de uma sociedade feudal, ajudam a desenvolver a ideia de que Lidia está sempre sendo vigiada, por todos. Esse olhar é marcante, pois é instrumento de controle e vigilância de todos os outros que fazem parte do círculo do castelo, ao mesmo tempo em que supostamente carrega a função de deixá-la protegida do que seriam os perigos de fora. O castelo surge, de início, como um espaço de ilusão de perfeição, organização e contenção, uma imagem da ordem social vigente que vai se desfazendo conforme Lidia se permite olhar para dentro de si - "Na verdade, já estava na hora de sair de seu esconderijo, mas ela ainda necessitava de silêncio, de um 
momento sozinha. Sua irmã Nia nunca entendeu. Mas Stephen... ele havia compreendido" (BACIGALUPI, 2010, p.25-26, tradução própria) ${ }^{2}$ - e para fora do castelo:

Eles deixavam a grandiosa construção cinzenta do castelo de Belari e caminhavam cuidadosamente através das montanhas, com Stephen sempre a ajudando, guiando seus passos frágeis entre os campos de margaridas, colombinas e tremoceiros, até que olhassem do alto, além do penhasco rochoso, para a cidade lá embaixo. (BACIGALUPI, 2010, p.35, tradução própria) $)^{3}$

Pode-se ainda mencionar a relação entre Burson e Lidia, por suas possíveis conexões com o castelo, pois ele age como parte da imagem monstruosa que se camufla, como parte integrante daquele espaço. Os dois - o castelo e Burson - durante a narrativa, atingem certos pontos de correspondência em sua solidez e força. Ele, sempre capaz de desaparecer ao integrar-se ao seu redor, e de aparecer, somente quando necessário, como parte importante no aprisionamento de Lidia, visto que, como chefe da segurança, tinha a função de vigiá-la e encontrá-la aonde quer que fosse; ao fim da narrativa, ao libertá-la de seu olhar, Burson parece não oferecer mais ameaças a ela, enquanto Lidia sente que perde o medo de agir. E assim como Burson, o castelo também perde sua função, como possível prisão para ela. Naquele momento, Lidia fica livre para tomar a decisão mais importante de sua vida.

2 "In truth, it was already time to leave her hidey-hole, but still she craved the silence, the moment alone. Her sister Nia never understood. Stephen though... he had understood"

3 "They would leave the great gray construct of Belari's castle and walk carefully across the mountain meadows, Stephen always helping her, guiding her fragile steps through fields of daisies, columbine, and lupine until they peered down over sheer granite cliffs to the town far below" 
Entretanto, o castelo não cumpre apenas a função de representar o locus horribilis típico do gótico; seu significado é expandido pela ideia de contraste entre quem está no topo da montanha e quem está abaixo dela, quem está integrado à organização do castelo e quem está fora dele, incluindo as comunidades na costa que, segundo Stephen, o único amigo de Lidia, são um último resquício de uma sociedade democrática, ou a própria montanha, um espaço associado à natureza e à suspensão da ordem social. A imagem do castelo, assim, agrega valores socioeconômicos e políticos ao estabelecer essas diferenças, uma vez que ele se torna um microcosmo das relações de poder que estruturam a sociedade como um todo. Percebemos essas ideias quando compreendemos que esse espaço só parece ser uma fonte de terror para Lidia e Stephen, enquanto todos os outros personagens parecem se submeter à ilusão criada por Belari.

O castelo, portanto, é uma representação da sociedade distópica delineada em "The Fluted Girl", à qual os personagens principais do conto estão presos, e, ao mesmo tempo, uma representação física do poder de Belari. Nesse sentido, ele é uma extensão do corpo de Belari, uma projeção dela própria. Se, como indicado acima, ele apresenta uma organização, por outro lado ele também é labiríntico, insinuando que o poder é intrincado, misterioso ou mesmo incompreensível - uma organização monstruosa. Pois o corpo de Belari também é monstruoso, ainda que não exatamente da mesma forma que o corpo de Lidia. Belari também teve seu corpo moldado artificialmente, a partir do cálculo matemático do que seria a beleza perfeita e de pesquisas de mercado junto a grupos de opinião. Assim, ele é um produto 
calculado para agradar ao público. O resultado é uma beleza fria como as pedras do seu castelo. Belari, apesar de todo o seu poder, é também uma mercadoria a ser consumida, um objeto de desejo para os outros, cuja carreira é controlada por seu agente, que se apropria de boa parte dos lucros que ela obtém.

Ainda que misture as categorias do natural e do artificial, do orgânico e do matematicamente calculado, o corpo de Belari é monstruoso não tanto por se mostrar intersticial, como no conceito de monstro de Carroll, mas por ser uma encarnação dos medos e anseios de uma determinada cultura, como propõe Jeffrey Cohen na sua primeira tese sobre o monstro $(1996$, p.4) - e, como o monstro de Cohen, ele é um objeto que deve ser lido e que revela, de forma didática, algo para além dele. Este é mais um exemplo de como a apropriação de elementos góticos pode ser produtiva para a construção da narrativa distópica. A monstruosidade não só intensifica o caráter sombrio desse tipo de narrativa, mas também oferece um emblema que condensa de forma concreta os principais pontos da crítica social desenvolvida pela distopia.

No caso específico da vilã de "The Fluted Girl", delineia-se de forma concisa a interferência de interesses econômicos sobre a própria constituição da subjetividade, a instrumentalização do corpo, a alienação do desejo numa lógica de consumo e a perversão embutida no culto às personalidades. Se, para Cohen, o monstro desafia qualquer limite ou fronteira (1996, p.7), a incorporação desses traços de ansiedades socioculturais na figura monstruosa da vilã aponta para o perigo de constante expansão e penetração da organização distópica em todos os indivíduos e nos espaços que eles habitam. Os elementos distópicos penetram nos personagens 
numa reprodução constante, para a qual o labirinto do castelo, com suas salas sem fim, também serve de imagem. A própria ideia de reprodução se converte num traço distópico: reprodução de antigas práticas de poder, das imagens geradas para o consumo, do espetáculo, da juventude de corpos suspensos no tempo através de drogas que prometem a imortalidade.

A ação da droga Revitia, que mantém o corpo de Belari eternamente jovem e o de Lidia à beira da adolescência é um dos fatores que mostram a problemática em construir a subjetividade no conto. As comparações entre Mirriam e Lidia são um exemplo disso, pois não se resumem à questão corporal, pelo fato de uma ser considerada mulher, e a outra, criança: "Quando elas chegaram a Belari, Mirriam e a garota flautada tinham a mesma altura. Agora, Mirriam era uma mulher crescida, meio metro mais alta do que Lidia, e feita para satisfazer um homem" (BACIGALUPI, 2010, p.26, tradução própria) ${ }^{4}$. Essas comparações também envolvem o tipo de comportamento que ambas exibem dentro daquela sociedade: "E ela [Mirriam] era leal. Ela era uma boa criada para Belari. Sempre sorrindo, feliz em servir. Todos eles eram assim quando chegavam da cidade ao castelo: Mirriam, a garota flautada, e sua irmã Nia" (BACIGALUPI, 2010, p.26, tradução própria) ${ }^{5}$. O fato de Lidia se esconder já revela sua necessidade em resistir, em preservar sua individualidade, demonstrando a ironia de que, apesar de se considerar inferior, como menina, ela já não é mais tão ingênua

4 "When they both came to Belari, the fluted girl and Mirriam had been the same height. Now, Mirriam was a grown woman, a full two feet taller than the fluted girl, and filled out to please a man"

5 "And she was loyal. She was a good servant for Belari. Smiling, happy to serve. They'd all been that way when they came up from the town to the castle: Mirriam, the fluted girl, and her sister Nia" 
na sua lealdade cega. Nesse aspecto, ela é a mulher que Mirriam, apesar de seu corpo, não é:

Sim, eu sou uma garota egoísta, ela pensou. Eu sou uma garota egoísta e você é uma mulher, e ainda assim temos a mesma idade, e eu sou mais esperta do que você. [...] Eu estou acima de você, e estou te observando, assim como Stephen nos observava. (BACIGALUPI, 2010, p.27, tradução própria) ${ }^{6}$

Essa diferença de postura entre Mirriam e Lidia pode ser explicada em parte pelo fato de a menina flautada ter, de certa forma, um olhar deslocado. Como parte de seu processo de transformação, Belari trocara seus olhos originais pelos olhos negros de uma menina desconhecida. Lidia não sabe de onde vieram seus novos olhos, mas imagina que pertenciam a uma menina indiana, que agora perambula às cegas numa aldeia distante. A troca dos olhos reafirma o caráter do corpo de Lidia como uma construção, uma espécie de mecanismo cujas peças são intercambiáveis ou substituíveis. Também reforça a ligação dessa construção a uma prática aquisitiva que se estende para além do feudo de Belari, fazendo parte de uma circulação global de mercadorias. A referência à indiana cega chama atenção para a exploração embutida nessa circulação, e Lidia se identifica com a outra menina, o que lhe permite se colocar na posição de subalterna ou tomar uma consciência mais clara dessa posição do que Mirriam, que permanece cúmplice de sua senhora. Lidia, assim, literalmente enxerga pelos olhos do outro. Uma estratégia formal comum tanto no gótico quanto na ficção científica é a representação de conceitos 6 "Yes, I am a selfish girl, she thought. I am a selfish girl, and you are a woman, and yet we are the same age, and I am smarter than you [...] I am above you, and I am watching you, just as Stephen watched us all" 
abstratos através de imagens ou objetos concretos. Assim como o castelo é uma representação física do funcionamento do poder, os olhos deslocados de Lidia funcionam como uma imagem concreta da empatia necessária para se chegar a uma consciência da estrutura social e de sua própria situação nessa estrutura.

O episódio dos olhos roubados de Lidia demonstra que a afirmação do poder de Belari se estende à natureza. Ela faz questão não só de modificar os olhos de Lidia e Nia, mas também espalha seu controle sobre as plantas, fazendo de objetos orgânicos, inorgânicos, retirando, de certa, forma, sua vitalidade na tentativa de (re)aproximá-los de uma ideia de beleza própria, que vai desde as flores - "Lidia passou as mãos pelas orquídeas: uma de Singapura; outra de Chennai; outra, listrada como um tigre, projetada por Belari" (BACIGALUPI, 2010, p.28, tradução própria)7, até os olhos: “'Quando eu a peguei, ela tinha os olhos azuis mais bonitos. Da cor das flores que você encontra aqui nas montanhas no verão'. Ela balançou a cabeça. 'Eu fiz com que fossem trocados. Eles eram bonitos, mas não para a imagem que eu estava buscando'" (BACIGALUPI, 2010, p.38, tradução própria) ${ }^{8}$. Olhos e flores são equivalentes na sua perda de organicidade, com a desculpa de uma melhora através de um aperfeiçoamento científico, ligado à manipulação dos limites biológicos. Nesse sentido, a noção de aprisionamento, na sociedade distópica apresentada por Baciagalupi, não se limita a Lidia, e ela sabe disso: "Nós somos belas prisioneiras, ela pensou.

7 "Lidia slipped through the orchids: one from Singapore; another from Chennai; another, striped like a tiger, engineered by Belari"

8 "When I got her, she had the most beautiful blue eyes. The color of the flowers you find here in the mountains in the summer.' She shook her head. 'I had them replaced. They were beautiful, but not the look I wished for" 
Assim como você" (BACIGALUPI, 2010, p.28, tradução própria) 9 . Ao se comparar com a flor criada por Belari, ela usa a primeira pessoa do plural para indicar que tanto ela quanto a sua irmã, Mirriam e, de certa forma, até a própria Belari são prisioneiras do mesmo sistema.

Ainda no que diz respeito aos instrumentos de controle representados no conto, é interessante notar o contraste entre as noções de joia que o texto oferece. Primeiramente, a palavra joia aparece como acessório que funcionaria como parte do instrumento de controle sobre Lidia: "Enrolou-se em volta de seu braço fino, como uma cobra, tilintando enquanto se fechava" (BACIGALUPI, 2010, p.29, tradução própria) ${ }^{10}$. Fazendo com que a eletricidade passasse através do corpo ao menor sinal de desobediência, essa joia funciona como um bracelete que aponta para o domínio sobre o outro através da dor; no entanto, esse instrumento de certa forma se torna ineficaz, pois não se mostra adequado à imagem que Belari quer construir para a performance de Lidia com sua irmã, o que a leva a exigir que Burson a retire. Para além dessa ideia, existe também a preciosidade, o brilho, a vivacidade que está ligada à imagem da cidade: "Nas profundezas de um pequeno vinco do vale das montanhas, a cidade brilhava com luzes âmbar" (BACIGALUPI, 2010, p.34, tradução própria) ${ }^{11}$. A noção de joia, por fim, é ligada ao frasco de veneno que Stephen dá para Lidia como opção de fuga, através do suicídio, o qual possui um certo brilho, uma vitalidade, uma luz, especialmente para Lidia: "Lidia fez sua exibição como havia sido treinada, mas em sua mão

9 "We are beautiful prisoners, she thought. Just like you"

10 "It writhed around her thin arm, snakelike, chiming as it locked"

11 "Deep in the tight crease of the mountain valley, the town shimmered with amber lights" 
o frasco estava suando, uma pequena joia de destino e poder" (BACIGALUPI, 2010, p.47, tradução própria) ${ }^{12}$. Dessa forma, se o instrumento de controle inicial falha, pois é joia esteticamente dissonante, o frasco permite, enquanto joia poderosa, se tornar um instrumento de controle sobre o próprio destino.

Outro tipo de retorno do passado, desta vez ligado à memória emocional e à resistência, está ligado justamente ao frasco. Stephen é o passado que se apresenta através das lembranças de Lidia, como forma de evidenciar os pensamentos contrários, libertários e rebeldes através da imagem do outro, uma vez que era Stephen quem buscava comunicar essas ideias para ela. Assim, ele é a incorporação de um passado que Lidia não pode se permitir esquecer, enquanto parte de uma vida presente que continua, mesmo na sua ausência, através da memória, como voz auxiliadora, mas ao mesmo tempo confrontadora da realidade na qual ela vive. O frasco deixado por Stephen funciona como uma espécie de mecanismo fantasmagórico que não a deixa esquecer-se do passado, e que, como objeto, pode ser a "chave" para mudar o seu futuro.

O passado também faz parte das percepções das estações do ano, ao marcar as mudanças sofridas por Lidia:

O cheiro acolhedor e rico da vegetação a fez lembrarse do verão, mesmo com o inverno que cortava as montanhas ao redor do castelo. Quando ela e Nia eram mais novas, antes de suas cirurgias, elas haviam corrido pelas montanhas, entre os pinheiros. (BACIGALUPI, 2010, p.28, tradução própria) $)^{13}$

12 "Lidia performed as she had been trained, but in her hand the vial lay sweaty, a small jewel of power and destiny"

13 "The rich warm smell of greenery reminded her of summer, despite the winter season that slashed the mountains around the castle. When she and Nia had been younger, before their surgeries, they had run in the mountains, amongst the pines" 
O verão, nesse caso, é a estação que carrega Lidia para o passado, de forma melancólica, marcada pela liberdade de movimento que possuía, mas que também não passa de uma ilusão, já que naquele momento era inverno, estação lembrada como força que acaba por vencer o verão:

Rajadas de vento derrubavam o gelo dos pinheiros, fazendo redemoinhos em grandes nuvens de tornado ao redor da aristocracia recémchegada. Os convidados se apressavam pela nevasca enquanto as luzes azuis da patrulha de ski de Burson deixavam sua marca pelas florestas. (BACIGALUPI, 2010, p.35, tradução própria) ${ }^{14}$

A presença do inverno é tão poderosa quanto a presença da aristocracia e a constante vigilância de Burson e, dessa forma, parece infinita.

Entretanto, são essas lembranças pessoais do passado que acabam empurrando Lidia para a revolta. E o momento da crise se instala justamente quando se comete um ultraje final contra o corpo de Stephen, que fora morto por Belari depois de uma tentativa frustrada de assassiná-la. Numa cena de grotesca violência, o corpo do rapaz é servido como canapés no banquete organizado por Belari para apresentar Lidia e Nia aos produtores dos canais de entretenimento.

Ao tomar conhecimento do uso da carne de Stephen como comida da festa, Lidia encontra força suficiente para agir, de forma decisiva para seu futuro. Stephen vira alimento, tanto literal, para os participantes do banquete, quanto metafórico, para Lidia.

14 "Gusts of wind tore snow from the pines and sent it swirling in great tornado clouds around the arriving aristocracy. The guests hurried through the driving snow while the blue search beams of Burson's ski patrols carved across the forests" 
Mesmo assim, se somarmos essa cena de canibalismo à posição de Lidia, que se encontra constantemente escondida entre os alimentos, na despensa, podemos observar como os dois se tornam a representação mais baixa da cadeia alimentar metafórica, enquanto consumo para os mais poderosos.

Esse tipo de representação do alimento, portanto, também é usado para mostrar o controle e o poder sobre o outro. Belari apresenta a carne de Stephen como alimento porque pode fazêlo, enquanto que para Lidia, a possibilidade de deixar de tornar-se alimento para outros - fosse através da servidão quanto literalmente após seu suicídio - é o que a faz mudar de ideia, tomando controle de sua vida: ao invés de matar a si mesma, decide usar o conteúdo do frasco para matar Belari. Nesse momento, ao derramar o conteúdo do frasco em um morango, a fruta pela qual Belari tem preferência - além de ser uma forma de suprir sua dependência por doces que é um efeito da droga recreativa Tingle - Lidia se torna capaz de expor a fraqueza do outro, mesmo que também fosse necessário oferecer o que, para ela, era o que restava de Stephen, invertendo sua posição na cadeia de dominação. Então, ironicamente, no último momento, ela decide abandonar a ideia de uma morte doce, ao dar o morango com o conteúdo do frasco para Belari, oferecendo-Ihe um destino amargo. Nesse sentido, os momentos finais do conto se tornam também uma paródia de entrega do corpo e sangue, transubstancial, aqui não por um ritual religioso, ainda que o ato de oferecer o morango a Belari seja amostra de subserviência de sua serva; desse modo, o sacrifício de Stephen, uma oferenda bem mais profana, fornece a possibilidade de um renascimento para Lidia. 
Assim, é significativo que o clímax do conto esteja ligado um espetáculo grotesco de canibalismo que parece uma versão paródica dos excessos de violência do gótico. Como já vimos, "The Fluted Girl" promove o retorno do passado feudal através de uma retomada paródica do gótico sob a chave do excesso. Isso torna possível traduzir a desigualdade social que faz parte de seu discurso distópico nos termos do domínio de uma aristocracia que prevalece como parte manipuladora dos princípios científicos e capitais do feudo. Essa aristocracia tem um poder tão absoluto que parece, de acordo com as visões apresentadas pelo narrador, colaborar com o percurso apagador da democracia, que se situa no limiar de sua existência, exatamente como resistência de uma ideia libertadora - principalmente através da figura de Stephen, que estabelece a conexão entre um passado possível e um futuro esperançoso. É justamente na representação dessa aristocracia pela chave do exagero paródico que essa possibilidade de abertura se insinua no texto, fornecendo um alvo específico em meio a uma estrutura de poder que parece funcionar de modo mais disperso, pois está calcada em relações de poder que envolvem todos os agentes sociais. O próprio excesso do canibalismo no final da narrativa aponta para o horror do poder da aristocracia midiática do conto, mas a empurra também para o ridículo de uma vilania de opereta. Em "The Fluted Girl", como em outras obras paródicas,

O passado é sempre colocado criticamente - e não nostalgicamente - em relação com o presente. [...] Nesse caso, a auto-reflexividade paródica conduz, paradoxalmente, à possibilidade de uma literatura que, enquanto afirma sua autonomia modernista como arte, também consegue, 
ao mesmo tempo, investigar suas relações complexas e íntimas com o mundo social no qual é escrita e lida. (HUTCHEON, 1991, p.70)

Nós, como leitores, vamos sendo levados - mesmo que pelo narrador em terceira-pessoa - ao olhar que Lidia possui sobre sua origem e sobre a origem dos males que a atinge. Nesse percurso, de dentro para fora e ao mesmo tempo de fora para dentro, ao perceber os mecanismos daquela sociedade e as suas próprias necessidades como "resto humano", é que ela pode reverter a ideia de cadeia que a prende aos outros seres ao seu redor. E essa cadeia é regida pela sobrevivência de quem consegue compreender seus mecanismos.

Poder, dinheiro e conhecimento são elementos que, para Lidia, parecem ser fundamentais para uma imagem de governo/ governante que só Belari poderia oferecer de modo suficiente. Ela, enquanto escuta o discurso de Stephen sobre as possibilidades de mudanças, vindas do próprio passado que aparentemente foi apagado por outros para a manutenção do poder, não consegue de início se desvincular de sua dependência diante da ilusão e manipulação estabelecida por Belari. Então, nesse período de submissão, gostar e respeitar se tornam sinônimos, cujos significados são questionados por Stephen, pondo em questão a percepção que aqueles que fazem parte do círculo controlado por Belari têm de sua senhora. Contudo, enquanto conversam, Stephen e Lidia ainda são reflexo da submissão pela ironia sublinhada pelo narrador, em que os dois se mantêm presos a ilusões de superioridade entre eles, já que um acusa o outro de maior subserviência enquanto ainda eram explorados pelos limites de lealdade e obediência a Belari. 
Desse modo, o conhecimento se torna essencial para uma possível libertação de Lidia. É a partir dessa transformação pelo conhecimento tanto da situação de outros, quanto da sua posição naquela sociedade, que entendemos a importância da cena final, que parte da mudança de olhar de Lidia ao decidir não cometer suicídio. Esse ato poderia, por um lado, reduzir as chances de Belari de exercer seu poder sobre seu corpo e aumentar seu poder sobre a comunidade, incluindo seu agente, mas, por outro lado, permitiria que esse mesmo sistema continuasse no futuro através de cobaias como a sua irmã. Por isso, a decisão de oferecer o morango envenenado para Belari - elemento doce, de pura subserviência e agrado - demonstra sua independência e capacidade de tomar decisões que poderiam ter consequências mais benéficas tanto para ela quanto para os outros. Por fim, o narrador, depois dessa reviravolta, acaba jogando com a ideia de desconhecimento da parte do leitor, sobre o futuro trazido pelas ações de Lidia. Será que Belari aceitou o morango? E se aceitou, será que morreu? Depois de sua morte o que resta para Lidia? O sistema muda ou mudam apenas as pessoas no poder? Essas questões permanecem com o leitor, mas, a partir dos apontamentos anteriores e do que podemos observar na nossa própria sociedade, a quebra dessa cadeia é muito mais difícil do que se imagina e talvez por isso a incerteza trazida pelo fim seja necessária, nesses tempos incertos de hoje. Como fazer? Por que fazer? Vale a pena arriscar a vida pela possibilidade de destruição de parte dessa cadeia?

Em seu conto, Paolo Bacigalupi foi capaz de fazer uma excursão distópica com contornos góticos. Ao trazer à tona 
questões sociais como democracia e liberdade de expressão de forma a delinear o comportamento de suas personagens, 0 texto passa a ser tão ou mais atual do que era na época de sua publicação. Cerca de dezesseis anos mais tarde, a instabilidade das posições sociopolíticas, principalmente quando observamos como os ideais da democracia em certo países, inclusive no Brasil, vêm sendo ameaçados, continua atual. Sendo assim, a visão distópica apresentada por Bacigalupi acaba por se aproximar da realidade, ao apresentar figuras usurpadoras de seu poder, em uma comunidade de uma idolatria cega que se deixa manipular através da mídia e de um discurso de salvação. Essa talvez seja a maior ironia do autor, fazer uso de uma narrativa distópica para denunciar a possibilidade de continuidade de questionamentos feitos pelo movimento gótico desde o século XVIII, apontando para semelhanças possíveis com a sociedade atual, que só se tornariam claras por essa aproximação. Se a nossa sociedade, enquanto democrática, é parte do passado da sociedade apresentada nessa distopia, parece ser imprescindível observar como o gótico é utilizado pelo conto.

A decisão do autor de abarcar as noções de aprisionamento do sujeito, além das dificuldades de lidar com o passado, funciona tanto como marca do gótico quanto marca da atualidade. Além disso, "The Fluted Girl", através das marcas corporais das figuras de suas personagens, entendidas como monstruosas, é capaz ainda de evidenciar questões importantes para o gótico, como o excesso e a instabilidade social, também centrais para o discurso distópico e que, ao se deslocarem para uma forma paródica, alcançam seu objetivo de forma mais complexa: 
Em certo sentido, a paródia é uma forma pós-moderna perfeita, pois, paradoxalmente, incorpora e desafia aquilo a que parodia. Ela também obriga a uma reconsideração da ideia de origem ou originalidade, ideia compatível com outros questionamentos pósmodernos sobre os pressupostos do humanismo liberal (HUTCHEON, 1991, p.28).

Assim, a apropriação do gótico em "The Fluted Girl", mais do que simplesmente intensificadora dos aspectos mais sombrios da distopia representada no texto, é parte integrante da maneira como essa distopia é imaginada, sendo um elemento central para a construção de significado do conto e para a problematização de seus sentidos.

\section{REFERÊNCIAS}

BACIGALUPI, Paolo (2010). "The Fluted Girl". In: Pump Six and Other Stories. San Francisco: Night Shade Books.

BAUMAN, Zygmunt (2008). "Utopia in the Age of Uncertainty". In: Liquid Times: Living in an Age of Uncertainty. 2.reimp. Cambridge (UK); Malden (MA): Polity.

BOOKER, M. K (1994). The Dystopian Impulse in Modern Literature: Fiction as Social Criticism. Westport (CT); London: Greenwood Press.

BOTTING, Fred (1999). Gothic. Nova York; Londres: Routledge.

CARROLL, Noël (2004). The Philosophy of Horror or Paradoxes of the Heart. Nova York; Londres: Routledge.

COHEN, Jeffrey Jerome (1996). “Monster Culture (Seven Theses)”. In: (Org.). Monster Theory: Reading Culture. Mineápolis; Londres: U. of Minnesota Press. p.3-25. ELLIS, Markman (2003). The History of Gothic Fiction. Edimburgo: Edinbourgh UP. FOUCAULT, Michel (2006). Surveiller et punir: naissance de la prison. Paris: Gallimard. FRANÇA, Júlio (2016). "O Gótico e a presença fantasmagórica do passado". In: Anais eletrônicos do XV encontro da ABRALIC, v.1. Rio de Janeiro: Dialogarts. p.2492-2502. 
HUTCHEON, Linda (1991). Poética do pós-modernismo: história, teoria, ficção. Rio de Janeiro: Imago.

MARQUES, Eduardo Marks de (2013). "I Sing the Body Dystopic: Utopia and Posthuman Corporeality in P.D. James's The Children of Men". Ilha do Desterro, 65, 29-48.

(2014). "Da centralidade política à centralidade do corpo transumano: movimentos da terceira virada distópica na literatura". Anuário de Literatura, 19(1), 10-29.

PUNTER, David; BYRON, Glennis (2004). The Gothic. Malden (MA); Oxford: Blackwell.

PUNTER, David (2013). The Literature of Horror, vol. 1: The Gothic Tradition. 2.ed. Nova York; Londres: Routledge.

RADCLIFFE, Ann (2008). The Mysteries of Udolpho. Oxford: Oxford UP. (2017). The Italian or The Confessional of the Black Penitents: A Romance. Oxford: Oxford UP.

ROSE, Margaret A. (1993). Parody: Ancient, Modern and Post-Modern. Cambridge: Cambridge University Press.

SIBILIA, Paula (2015). O homem pós-orgânico: a alquimia dos corpos e das almas à luz das tecnologias digitais. 2.ed. Rio de Janeiro: Contraponto.

VARSAM, Maria (2003). "Concrete Dystopia: Slavery and Its Others". In: BACCOLINI, Raffaella; MOYLAN, Tom (Orgs.). Dark Horizons: Science Fiction and the Dystopian Imagination. Nova York; Londres: Routledge. p.203-224. 